\title{
Identification and Susceptibility Profile of Vaginal Candida Species to Antifungal Agents among Pregnant Women Attending the Antenatal Clinic of Thika District Hospital, Kenya*
}

\author{
Menza Nelson $^{1 \#}$, Wanyoike Wanjiru ${ }^{2}$, Muturi Margaret ${ }^{1}$ \\ ${ }^{1}$ Department of Medical Laboratory Sciences, Kenyatta University, Nairobi, Kenya \\ ${ }^{2}$ Department of Botany, Jomo Kenyatta University of Agriculture and Technology, Nairobi, Kenya \\ Email: margaretmw2000@yahoo.com,wanjiru_wanyoike@yahoo.com, ${ }^{\#}$ menzanelson2010@gmail.com
}

Received August 30, 2013; revised September 30, 2013; accepted October 7, 2013

Copyright (C) 2013 Menza Nelson et al. This is an open access article distributed under the Creative Commons Attribution License, which permits unrestricted use, distribution, and reproduction in any medium, provided the original work is properly cited. In accordance of the Creative Commons Attribution License all Copyrights (C) 2013 are reserved for SCIRP and the owner of the intellectual property Menza Nelson et al. All Copyright (C) 2013 are guarded by low and by SCIRP as a guardian.

\begin{abstract}
Fungal infections have emerged as a world-wide health care problem in recent years, owing to the extensive use of broad-spectrum antibiotics. We screened 104 pregnant women with symptoms of vaginal candidiasis in the antenatal clinic of Thika District Hospital, Kenya in order to identify vaginal Candida species and determine their susceptibility profile to commonly used antifungal drugs for treatment of the infection. The drugs tested were fluconazole, ketoconazole, itraconazole, clotrimazole and topical nystatin. Vaginal swabs were collected and subjected to mycological and biochemical tests for Candida species identification. Susceptibility profile of the identified vaginal Candida species to the antifungal drugs was carried out using broth micro-dilution minimum inhibiting concentration method based on the approved National Committee for Clinical Laboratory Standards (NCCLS, 2002) guidelines. Candida albicans was susceptible to most of the azoles drugs while the other species had varying responses. Candida krusei and Candida glabrata species isolated were resistant to fluconazole and ketoconazole. Candida albicans isolates had a high susceptibility to itraconazole $(88.33 \%)$. Five percent $(5 \%)$ of the isolates were susceptible in dose dependent (S-DD) with Minimum Inhibitory Concentrations (MICs) of $0.25-0.5 \mu \mathrm{g} / \mathrm{ml}$ while $11.67 \%$ of C. albicans isolates were resistant (MICs $\geq 1 \mu \mathrm{g} / \mathrm{ml}$ ). Itraconazole resistance was highest among C. glabrata isolates $(50 \%)$ while $32.14 \%$ were S-DD (MICs $0.25-0.5 \mu \mathrm{g} / \mathrm{ml}$ ). Only $17.85 \%$ of the C. glabrata isolates were susceptible (MICs of $\leq 0.125 \mu \mathrm{g} / \mathrm{ml}$ ). All isolates of Candida isolates were susceptible to itraconazole and clotrimazole except $C$. krusei which was $100 \%$ resistant to clotrimazole. All Candida species isolates had low susceptibility to topical nystatin except Candida parapsilosis that was $100 \%$ susceptible. Data also showed an emerging resistance of Candida krusei to most of the drugs used except itraconazole. The results of this study support the continued use of these antifungal drugs for the treatment of vaginal candidiasis in the pregnant women except topical nystatin.
\end{abstract}

Keywords: Pregnant Women; Vaginal Candidiasis; Candida Species; Antifungal Drugs; Susceptibility Profile

\section{Introduction}

Multidrug resistant microorganisms are becoming a major challenge worldwide because of irrational use of antibiotics and the increasing population of immunocompromised individuals [1]. In the last two decades, there

"Conflict of interest statement: The authors have no conflict of interest concerning the work reported in this paper.

${ }^{\#}$ Corresponding author. has been a steady increase in the incidence of systemic opportunistic fungal infections especially in Sub-Sahara Africa [2]. This rise is associated with Acquired Immunodeficiency Syndrome (AIDS) pandemic, prolonged antimicrobial therapy, invasive procedures and immunosuppressive therapy [3]. Vaginal Candida species are emerging as significant opportunistic organisms that have increased over the past few decades [4].

The available treatment for vaginal candidiasis in- 
cludes azoles (fluconazole, ketoconazole, itraconazole, voriconazole and clotrimazole) and polyene antifungals such as nystatin and amphotericin B. However, in Thika District Hospital where the study was conducted, azole antifungal drugs (fluconazole, ketoconazole, itraconazole and clotrimazole) and topical nystatin are the drugs of choice prescribed to pregnant and non-pregnant women for the treatment of vaginal candidiasis (according to the Hospital health records).

In Kenya, there are few data on Candida's role in causing vaginal candidiasis in pregnant women and its antifungal susceptibility [5]. In the recent past, reports of research done in Kenya on oral candidiasis indicated that there is an emerging resistance among Candida species to some of the antifungal drugs [1]. It is therefore necessary to investigate antifungal resistance of Candida species from clinical sources in order to determine any emerging resistance. The present study was therefore undertaken to evaluate the susceptibility profile of identified vaginal Candida species isolated from vaginal samples of pregnant women.

\section{Materials and Methods}

\subsection{Study Design}

Cross sectional study was adopted and susceptibility tests were carried out at Thika District Hospital Laboratory, Thika, Kenya.

\subsection{Sampling Technique}

Purposive sampling technique was used among the pregnant women with symptoms of vaginal candidiasis attending the antenatal clinic of Thika District Hospital.

\subsection{Study Approval and Ethical Consideration}

This study was approved by Kenyatta University and Thika District Hospital. The objectives of the study were explained to the pregnant women attending Thika District hospital antenatal clinic. Those who volunteered to participate in the study signed consent form after it was read and explained to them. They were assured that all the information regarding their participation would be confidential.

\subsection{Hypotheses}

All pregnant women attending the antenatal clinic of Thika District Hospital do not have vaginal candidiasis.

The vaginal Candida species isolated from pregnant women attending the antenatal clinic of Thika District Hospital are not resistant to the antifungal agents used.

\subsection{Sample Collection}

Vaginal swabs were collected from pregnant women with symptoms of vaginal candidiasis. The symptoms included itching, difficult in walking, dysuria and presence of thick adherent plaques on the vulval, vaginal or cervical epithelium. Samples collected were taken to the Hospital Laboratory for Candida species isolation, identification and drug susceptibility testing.

\subsection{Gram Stain}

The test was carried out essentially according to the procedure of Chander [6]. Gram stained smears were used to examine the presence of gram positive budding yeast cells with pseudohyphae. Specimen was considered as acceptable when 25 or more polymorphonuclear leukocytes were seen per low power field $(100 \times)$ with few (less than 10) squamous epithelial cells.

\subsection{Culture Procedure}

The samples were cultured on Saboraud dextrose agar (SDA) containing two percent chloramphenicol. Inoculated plates were incubated at $37^{\circ} \mathrm{C}$ and examined after 48 hours for cream coloured pastry colonies and budding yeast cells suggestive of Candida species. Isolates from SDA were inoculated on CHROMagar (France) using an inoculating needle and incubated at $37^{\circ} \mathrm{C}$ for 72 hours to ensure detection of mixed cultures by colour changes. The method is based on the differential release of chromogenic breakdown products from various substrates by Candida species following differential exoenzyme activity [7]. This test was used for presumptive identification of C. albicans, C. tropicalis and C. parapsilosis

\subsection{Germ Tube Test}

This method was used as a confirmatory test for identification of Candida albicans. A single colony of the test yeast cells from a pure culture was inoculated in human serum and incubated at $37^{\circ} \mathrm{C}$ for $2-4$ hours. A drop of the incubated serum was placed on a microscope slide and covered with a cover slip. The wet mounts were examined under the microscope to look for the presence of germ tube using the $40 \times$ objective according to Dalmau morphology method [7]. The isolates were classified as either germ tube positive or germ tube negative.

\subsection{Sugar Assimilation Test}

The test was carried out essentially according to the procedure of Lodder et al. [8]. The assessment of the ability of yeast to utilize carbohydrates was based on the use of carbohydrate-free yeast nitrogen base agar. Observation for the presence of growth around carbohydrate impregnated filter paper discs was done after incubation for 18 hours at $30^{\circ} \mathrm{C}$.

Carbohydrates used were glucose, galactose, lactose, 
maltose, sucrose, raffinose, trehalose and cellobiose. Presence of growth in the medium indicated the ability of the isolate to assimilate a sugar. The Candida species were identified using the sugar assimilation patterns for individual species by Lodder et al. [8].

\subsection{Antifungal Susceptibility Testing}

The test was carried out on the identified isolates using broth microdilution method of Hace et al. [9], and based on the proposed National Committees for Clinical Laboratory Standards (NCCLS) guidelines for the broth microdilution method as contained in document M27-A2 [10]. The antifungal drugs tested were fluconazole, ketoconazole, itraconazole, clotrimazole and topical nystatin.

Different concentrations of fluconazole and ketoconazole were prepared and tested as follows; fluconazole $(0.125-64 \mu \mathrm{g} / \mathrm{ml}$ and ketoconazole $(0.007-8 \mu \mathrm{g} / \mathrm{ml})$ as proposed by NCCLS, 2002 [10]. The concentrations of itraconazole ranged from 0.015 to $8 \mu \mathrm{g} / \mathrm{ml}$ [30] and $0.03-16 \mu \mathrm{g} / \mathrm{ml}$ for clotrimazole [2]. For the purposes of this study the final concentrations of topical nystatin ranged from $0.06-16 \mu \mathrm{g} / \mathrm{ml}[11]$.

The different antifungal drug dilutions were dispensed into a U-shaped microtiter plates (Greiner Bio-one, Holland). The test isolates were suspended in Roswell Park Memorial Institute (RPMI-1640 medium usually matched to $0.5 \mathrm{McFarland}$ standard suspensions. The mixture $0.1 \mathrm{ml}$ was inoculated into each microtiter wells containing different concentrations of the test drug. The inoculated microtiter plates were incubated at $35^{\circ} \mathrm{C}$ for 48 hours. The MICs for the azole drugs were read as the lowest antifungal concentration with substantially lower turbidity $(\sim 50 \%)$ compared to growth in the antifungal free growth control. Topical nystatin MICs were read as the minimal antifungal concentration with complete inhibition of growth (optical clarity). The test was carried out in duplicate in each concentration of the drugs and the mean was recorded. Quality control was ensured by testing the NCCLS-recommended quality control strains Candida parapsilosis ATCC 22019 and Candida krusei ATCC 6258.

We used the proposed standards for MIC interpretation criteria by NCCLS, 2002 [10] for fluconazole and ketoconazole. The isolates of Candida species with MICs of $<8 \mu \mathrm{g} / \mathrm{ml}$ for fluconazole were regarded susceptible (S); $16-32 \mu \mathrm{g} / \mathrm{ml}$ were susceptible in dose dependent (SDD) and $>64 \mu \mathrm{g} / \mathrm{ml}$ were resistant (R). Candida species isolates with MICs of $<0.125 \mu \mathrm{g} / \mathrm{ml}$ were susceptible; 0.25 $0.5 \mu \mathrm{g} / \mathrm{ml}$ were S-DD while $>1 \mu \mathrm{g} / \mathrm{ml}$ were resistant for ketoconazole. According to Gonzalez et al. [12], isolates with MICs of $\leq 0.125 \mu \mathrm{g} / \mathrm{ml}$ for itraconazole were regarded susceptible while MICs of $0.25-0.5 \mu \mathrm{g} / \mathrm{ml}$ were considered susceptible but in a dose dependent manner; MICs of $\geq 1 \mu \mathrm{g} / \mathrm{ml}$ were considered resistant [12]. This interpretation was used for this study too. Candida species isolates with MICs of $<0.5 \mu \mathrm{g} / \mathrm{ml}$ for clotrimazole were considered susceptible while those with MICs of $>0.5 \mu \mathrm{g} / \mathrm{ml}$ were considered resistant as suggested by Pelletier et al. [12]. The topical nystatin MICs of $\leq 1$ $\mu \mathrm{g} / \mathrm{ml}$ was adopted as susceptible breakpoint while $>1$ $\mu \mathrm{g} / \mathrm{ml}$ was regarded as resistance breakpoint as suggested by Sandra et al. [11].

\subsection{Quality Control Strains}

Prior to antifungal susceptibility testing each isolate was sub-cultured at least twice on SDA for 24 hours before use. This was to obtain a pure culture of each isolate. The Quality Control strain, Candida parapsilosis ATCC 22019 and Candida krusei ATCC 6258.

\subsection{Data Analysis}

All collected data were introduced into Microsoft Excel data sheet. The susceptibility of vaginal Candida species to the antifungal drugs was calculated using ANOVA to establish any variations. Chi-square test was used to test the susceptibility association of the two groups of the antifungal drugs used to the vaginal Candida species isolated. All the statistical analysis was carried out using MINITAB and SPSS version 13.0 computer package.

\section{Results}

In the present study, five (5) vaginal Candida species were isolated and identified. These species included Candida albicans, Candida glabrata, Candida krusei, Candida tropicalis and Candida parapsilosis. Candida albicans was the most frequently isolated species accounting for $63.83 \%$ of all the isolates, followed by Candida glabrata $(29.79 \%)$, Candida tropicalis (3.19\%), Candida krusei $(2.1 \%)$ and Candida parapsilosis with the least percentage isolates (1.06\%). Results on susceptibility of these vaginal Candida species to different antifungal agents are shown in Tables 1-5.

Fifty seven $(95 \%)$ Candida albicans isolates were susceptible (MICs of $<8 \mu \mathrm{g} / \mathrm{ml}$ ); $3.33 \%$ isolates were susceptible in dose dependent manner $(16-32 \mu \mathrm{g} / \mathrm{ml})$ and $1.67 \%$ were resistant (MICs $>64 \mu \mathrm{g} / \mathrm{ml}$ ) to flucona- zole. Candida glabrata (42.85\%) isolates had an MIC of $<8$ $\mu \mathrm{g} / \mathrm{ml}$ and were regarded susceptible to fluconazole. However, $50.01 \%$ of the isolates were susceptible in dose dependent (MICs of $16-32 \mu \mathrm{g} / \mathrm{ml}$ ) while $7.14 \%$ were resistant (MICs $>64 \mu \mathrm{g} / \mathrm{ml})$. High resistance $(100 \%)$ was recorded for Candida krusei since all the 2 isolates had an MIC of $>64 \mu \mathrm{g} / \mathrm{ml}$. Candida tropicalis and Candida parapsilosis were all susceptible to fluconazole since all their isolates had MICs of $<8 \mu \mathrm{g} / \mathrm{ml}$ (Table 1). The $\mathrm{MIC}_{90}$ to fluconazole was $64.0 \mu \mathrm{g} / \mathrm{ml}$ while $\mathrm{MIC}_{50}$ was $4.0 \mu \mathrm{g} / \mathrm{ml}$. 
Table 1. Susceptibility of Candida species to different concentrations of Fluconazole.

\begin{tabular}{|c|c|c|c|c|c|}
\hline Fluconazole $(\mu \mathrm{g} / \mathrm{ml})$ & C. albicans n (\%) & C. glabrata n (\%) & C. krusei n (\%) & C. tropicalis n (\%) & C. parapsilosis n (\%) \\
\hline 0.125 & $14(23.33)$ & $6(21.43)$ & NIL & NIL & NIL \\
\hline 0.25 & $24(40)$ & $1(3.57)$ & NIL & NIL & $1(100)$ \\
\hline 0.5 & 8 (13.33) & $2(7.14)$ & NIL & NIL & NIL \\
\hline 1.0 & $5(8.33)$ & NIL & NIL & $3(100)$ & NIL \\
\hline 2.0 & $2(3.33)$ & $1(3.57)$ & NIL & NIL & NIL \\
\hline 4.0 & $1(1.67)$ & $2(7.14)$ & NIL & NIL & NIL \\
\hline 8.0 & 3 (5) & NIL & NIL & NIL & NIL \\
\hline 16 & $1(1.67)$ & $10(35.72)$ & NIL & NIL & NIL \\
\hline 32 & $1(1.67)$ & $4(14.29)$ & NIL & NIL & NIL \\
\hline 64 & $1(1.67)$ & 2 (7.14) & $2(100)$ & NIL & NIL \\
\hline Total & $60(100)$ & $28(100)$ & $2(100)$ & $3(100)$ & $1(100)$ \\
\hline
\end{tabular}

$\mathrm{Nil}=$ No organism was detected at that concentration.

Table 2. Susceptibility of Candida species to different concentrations of Ketoconazole.

\begin{tabular}{|c|c|c|c|c|c|}
\hline Ketoconazole $(\mu \mathrm{g} / \mathrm{ml})$ & C. albicansn (\%) & C. glabrata n (\%) & C. krusei n (\%) & C. tropicalis n (\%) & C. parapsilosis n (\%) \\
\hline 0.007 & $4(6.67)$ & 7 (25) & NIL & NIL & NIL \\
\hline 0.014 & $27(45)$ & $1(3.57)$ & NIL & NIL & NIL \\
\hline 0.028 & $6(10)$ & $4(14.2)$ & NIL & 2 (66.67) & NIL \\
\hline 0.06 & $2(3.33)$ & $9(32.1)$ & NIL & NIL & $1(100)$ \\
\hline 0.125 & 16 (26.67) & $3(10.71)$ & NIL & 1 (33.33) & NIL \\
\hline 0.25 & $2(3.33)$ & NIL & NIL & NIL & NIL \\
\hline 0.5 & NIL & NIL & $1(50)$ & NIL & NIL \\
\hline 1.0 & 1 (1.67) & $1(3.57)$ & NIL & NIL & NIL \\
\hline 2.0 & $2(3.33)$ & NIL & $1(50)$ & NIL & NIL \\
\hline 4.0 & NIL & $2(7.14)$ & NIL & NIL & NIL \\
\hline 8.0 & NIL & $1(3.57)$ & NIL & NIL & NIL \\
\hline Total & $60(100)$ & $28(100)$ & $2(100)$ & $3(100)$ & $1(100)$ \\
\hline
\end{tabular}

Nil = No organism was detected at that concentration.

Fifty five $(91.67 \%)$ Candida albicans isolates were susceptible (MICs $<0.125 \mu \mathrm{g} / \mathrm{ml}$ ); 3.33\% were susceptible in dose dependent (MICs of $0.25-0.5 \mu \mathrm{g} / \mathrm{ml}$ ) while $5 \%$ of the isolates were resistant to ketoconazole (MICs $>1 \mu \mathrm{g} / \mathrm{ml})$. Candida glabrata isolates $(85.72 \%)$ were susceptible to the drug (MICs $<0.125 \mu \mathrm{g} / \mathrm{ml}$ ) and the remaining $14.28 \%$ were resistant (MICs $>1 \mu \mathrm{g} / \mathrm{ml}$ ). Candida krusei $(50 \%)$ isolates were susceptible in dose dependent (MICs of $0.25-0.5 \mu \mathrm{g} / \mathrm{ml}$ ) while $50 \%$ were resistant (MICs $>1 \mu \mathrm{g} / \mathrm{ml}$ ). Both Candida tropicalis and Candida parapsilosis were $100 \%$ susceptible to ketoconazole since all of their isolates had MICs of $>1 \mu \mathrm{g} / \mathrm{ml}$ (Table 2). The $\mathrm{MIC}_{90}$ to ketoconazole was $0.125 \mu \mathrm{g} / \mathrm{ml}$ while $\mathrm{MIC}_{50}$ was $0.014 \mu \mathrm{g} / \mathrm{ml}$.

Candida albicans isolates had a high susceptibility to itraconazole. Eighty three point three $(88.33 \%)$ percent of Candida albicans isolates had an MIC of $\leq 0.125$ $\mu \mathrm{g} / \mathrm{ml}$ and were regarded susceptible while $5 \%$ of the isolates were susceptible in dose dependent (MICs of $0.25-0.5 \mu \mathrm{g} / \mathrm{ml}$ ). Eleven point six seven percent (11.67\%) of Candida albicans isolates was resistant (MICs $\geq 1 \mu \mathrm{g} / \mathrm{ml}$ ) as shown in Table 3. All isolates of $C$. krusei, C. tropicalis and C. parapsilosis were susceptible to itraconazole (MICs of $\leq 0.125 \mu \mathrm{g} / \mathrm{ml}$ ) Table 3. Itraconazole resistance was highest among Candida glabrata isolates. Fifty percent $(50 \%)$ of the Candida glabrata isolates had MIC of $\geq 1 \mu \mathrm{g} / \mathrm{ml}$ and were regarded resistant while $32.14 \%$ were susceptible in dose dependent (MICs of $0.25-0.5 \mu \mathrm{g} / \mathrm{ml})$. Only $17.85 \%$ of the Candida glabrata isolates had an MIC of $\leq 0.125 \mu \mathrm{g} / \mathrm{ml}$ and were susceptible. The $\mathrm{MIC}_{90}$ to itraconazole was $4.0 \mu \mathrm{g} / \mathrm{ml}$ while $\mathrm{MIC}_{50}$ was $0.03 \mu \mathrm{g} / \mathrm{ml}$.

Candida albicans isolates were susceptible to clotrimazole. Sixty three point three percent $(63.3 \%)$ to $C$. 
Table 3. Susceptibility of Candida species isolates to different concentrations of Itraconazole.

\begin{tabular}{|c|c|c|c|c|c|}
\hline Itraconazole $(\mu \mathrm{g} / \mathrm{ml})$ & C. albicans n (\%) & C. glabrata n (\%) & C. krusei n (\%) & C. tropicalis n (\%) & C. parapsilosisn (\%) \\
\hline 0.015 & 27 (45) & NIL & NIL & NIL & $1(100)$ \\
\hline 0.03 & $3(5)$ & $3(10.71)$ & NIL & $2(66.67)$ & NIL \\
\hline 0.06 & $5(8.33)$ & $2(7.14)$ & NIL & NIL & NIL \\
\hline 0.125 & $15(25)$ & NIL & $2(100)$ & 1 (33.33) & NIL \\
\hline 0.25 & $2(3.33)$ & $1(3.57)$ & NIL & NIL & NIL \\
\hline 0.5 & 1 (1.67) & 8 (28.5) & NIL & NIL & NIL \\
\hline 1.0 & 1 (1.67) & NIL & NIL & NIL & NIL \\
\hline 2.0 & $2(3.33)$ & NIL & NIL & NIL & NIL \\
\hline 4.0 & $3(5)$ & $14(50)$ & NIL & NIL & NIL \\
\hline 8.0 & 1 (1.67) & NIL & NIL & NIL & NIL \\
\hline Total & $60(100)$ & $28(100)$ & $2(100)$ & $3(100)$ & $1(100)$ \\
\hline
\end{tabular}

NIL: No organism was detected at that concentration.

Table 4. Susceptibility of Candida species isolates to different concentrations of Clotrimazole.

\begin{tabular}{|c|c|c|c|c|c|}
\hline Clotrimazole $(\mu \mathrm{g} / \mathrm{ml})$ & C. albicans n (\%) & C. glabrata n (\%) & C. krusei n (\%) & C. tropicalis n (\%) & C. parapsilosis n (\%) \\
\hline 0.03 & $4(6.67)$ & $9(32.14)$ & NIL & NIL & NIL \\
\hline 0.06 & $10(16.67)$ & $3(10.71)$ & NIL & NIL & NIL \\
\hline 0.125 & $3(5)$ & $12(42.78)$ & NIL & 2 (66.67) & $1(100)$ \\
\hline 0.25 & $20(33.33)$ & $1(3.57)$ & NIL & NIL & NIL \\
\hline 0.5 & $1(1.67)$ & NIL & NIL & NIL & NIL \\
\hline 1.0 & $2(3.33)$ & NIL & $1(50)$ & NIL & NIL \\
\hline 2.0 & 7 (11.67) & NIL & NIL & $1(33.33)$ & NIL \\
\hline 4.0 & $2(3.33)$ & $2(7.14)$ & $1(50)$ & NIL & NIL \\
\hline 8.0 & $3(5)$ & NIL & NIL & NIL & NIL \\
\hline 16 & 8 (13.33) & 1 (3.57) & NIL & NIL & NIL \\
\hline Total & $60(100)$ & $28(100)$ & $2(100)$ & $3(100)$ & $1(100)$ \\
\hline
\end{tabular}

NIL: No organism was detected at that concentration.

albicans isolates had MICs of $\leq 0.5 \mu \mathrm{g} / \mathrm{ml}$ and were regarded susceptible while the rest $36.7 \%$ had an MIC of $>$ $0.5 \mu \mathrm{g} / \mathrm{ml}$ and were considered resistant (Table 4). Candida glabrata isolates had the highest in susceptibility to clotrimazole. Eighty nine point two nine percent (89.29\%) of the isolates had MICs of $\leq 0.5 \mu \mathrm{g} / \mathrm{ml}$ and were susceptible while $10.71 \%$ of the isolates were resistant (MICs $>0.5 \mu \mathrm{g} / \mathrm{ml}$ ). The other non Candida albicans species isolates were fairly susceptible to clotrimazole except Candida krusei where all the isolates had MICs of $>0.5 \mu \mathrm{g} / \mathrm{ml}$ and were regarded resistant. Out of the three (3) isolates of Candida tropicalis, 2 were susceptible (MICs $\leq 0.5 \mu \mathrm{g} / \mathrm{ml}$ ) while 1 isolate was resistant (MICs > $0.5 \mu \mathrm{g} / \mathrm{ml}$ ). The only isolate of Candida parapsilosis was susceptible to Clotrimazole (Table 4). The $\mathrm{MIC}_{90}$ of clotrimazole was $16 \mu \mathrm{g} / \mathrm{ml}$ while $\mathrm{MIC}_{50}$ was $0.25 \mu \mathrm{g} / \mathrm{ml}$.

Candida albicans isolates (41.67\%) were susceptible to topical nystatin. The isolates had MICs of $\leq 1 \mu \mathrm{g} / \mathrm{ml}$ while the rest $58.33 \%$ isolates had MICs of $>1 \mu \mathrm{g} / \mathrm{ml}$ and were resistant (Table 5). Forty two point eight six percent (42.86\%) of Candida glabrata isolates were susceptible (MICs $\leq 1 \mu \mathrm{g} / \mathrm{ml}$ ). Fifty seven point one four (57.14\%) of Candida glabrata isolates had MICs of $>1$ $\mu \mathrm{g} / \mathrm{ml}$ and were regarded resistant. One (1) isolate of Candida krusei was susceptible (MIC $\leq 1 \mu \mathrm{g} / \mathrm{ml}$ ) while the other one was resistant (MIC $>1 \mu \mathrm{g} / \mathrm{ml}$ ) as shown in Table 5. One (1) out of the three Candida tropicalis isolates was susceptible to topical nystatin (MIC $\leq 1 \mu \mathrm{g} / \mathrm{ml}$ ) while the two isolates $(66.67 \%)$ were resistant (MIC $>1$ $\mu \mathrm{g} / \mathrm{ml})$. The only isolate of Candida parapsilosis was susceptible to topical nystatin (MIC $\leq 1 \mu \mathrm{g} / \mathrm{ml}$ ). The $\mathrm{MIC}_{90}$ of topical nystatin was $16 \mu \mathrm{g} / \mathrm{ml}$ and $\mathrm{MIC}_{50}$ was 2 $\mu \mathrm{g} / \mathrm{ml}$. 
Table 5. Susceptibility of Candida species isolates to different concentrations of topical Nystatin.

\begin{tabular}{|c|c|c|c|c|c|}
\hline Topical Nystatin $(\mu \mathrm{g} / \mathrm{ml})$ & C. albicans n (\%) & C. glabrata n (\%) & C. krusei n (\%) & C. tropicalis n (\%) & C. parapsilosis $\mathrm{n}(\%)$ \\
\hline 0.06 & NIL & $2(7.15)$ & NIL & NIL & NIL \\
\hline 0.125 & $4(6.67)$ & $1(3.57)$ & NIL & NIL & NIL \\
\hline 0.25 & $5(8.33)$ & $1(3.57)$ & NIL & $1(33.33)$ & NIL \\
\hline 0.5 & 7 (11.67) & 5 (17.87) & NIL & NIL & $1(100)$ \\
\hline 1.0 & $9(15)$ & $3(10.71)$ & $1(50)$ & NIL & NIL \\
\hline 2.0 & $10(16.67)$ & 7 (25) & NIL & NIL & NIL \\
\hline 4.0 & 8 (13.33) & $2(7.14)$ & $1(50)$ & $2(66.67)$ & NIL \\
\hline 8.0 & $10(16.67)$ & 4 (14.29) & NIL & NIL & NIL \\
\hline 16 & 7 (11.67) & 3 (10.71) & NIL & NIL & NIL \\
\hline Total & $60(100)$ & 28 (100) & $2(100)$ & $3(100)$ & $1(100)$ \\
\hline
\end{tabular}

NIL: No organism was detected at that concentration.

\section{Discussion}

Increased multidrug resistant microorganisms are becoming a major challenge worldwide. The problem is attributed to inappropriate use of antibiotics and the increasing population of immune-compromised individuals [1]. Although multidrug resistant bacterial pathogens has been the main focus in the past, infection by yeasts account for $10 \%-15 \%$ of hospital infections [14]. In Thika District Hospital, azole antifungal drugs (fluconazole, ketoconazole, itraconazole and clotrimazole) and topical nystatin are usually prescribed to pregnant and non pregnant women for the treatment of vaginal candidiasis. It is also a common belief among some of women that the constant use of antifungal agents will prevent yeast infection [1]. Pregnant and non pregnant women usually use topical nystatin because it is cheaper than the azole drugs and commonly found over the counters. Emerging resistance among Candida species from clinical specimen to some of the antifungal drugs have been documented [1]. The present study evaluated the susceptibility of the identified vaginal Candida species isolates recovered from vaginal samples of pregnant women to fluconazole, ketoconazole, itraconazole, clotrimazole and topical nystatin.

The results of this study indicated that most Candida albicans (95\%) isolates were susceptible to fluconazole. The high fluconazole susceptibility in Candida albicans found in this study is consistent with other reports by Ogunbayo and Akortha [15,16]. Ogunbayo [15] reported a Fluconazole susceptibility of $96.3 \%$ among Candida albicans isolates in Nigeria while Akortha [16] reported a susceptibility of $95.7 \%$ among the Candida albicans isolates in the same country. This is probably due to the fact the drug is more tolerated with a wider spectrum of efficiency against Candida albicans. No fluconazole resistance was reported among yeast isolates in earlier studies on vulvovaginitis conducted in the United States,
England and Brazil [17,18]. Candida albicans isolates $(3.33 \%)$ were resistant to fluconazole (Table 1). This is consistent with other research findings for example; a U.S study reported fluconazole resistance of 3.6\% [17]. Akortha et al. [16] also reported a 4.3\% Candida albicans resistance in Edo state in Nigeria while a 2.1\% Candida albicans resistance was reported in New York [19].

As expected, higher MICs were recorded among Candida glabrata species isolates to fluconazole. Only $42.85 \%$ of Candida glabrata isolates were susceptible while the remaining $57.15 \%$ if the isolates were resistant (Table 1). This is due to the fact that Candida glabrata is innately less susceptible to fluconazole than most of other species of Candida [20]. This is in agreement with past studies by Pfaller et al. [5,20] and Kangogo et al. [2] that there has been an emerging resistance of Candida glabrata to fluconazole.

Candida krusei is intrinsically resistant to fluconazole even at high doses $[11,21,22]$. In this study, a $100 \%$ resistance was observed for Candida krusei, which is consistent with another research report, by Klastersky [22]. This is in agreement with past studies by Pfaller et al. [23] and Kangogo et al. [2] that there has been an emerged resistance of Candida krusei to fluconazole. The other non-albicans species isolated in this study; Candida tropicalis and Candida parapsilosis were all susceptible to fluconazole. This is in agreement with past studies by Pfaller et al. [23] that most of the non-albicans except Candida krusei are susceptible to fluconazole.

A similar susceptibility pattern to that of fluconazole was observed in ketoconazole (Table 2). This is because the two antifungal drugs are in the same group of antifungal drugs (azole drugs) and have a similar mode of action. The $91.67 \%$ susceptibility and $8.33 \%$ resistance of the drug to Candida albicans observed for ketoconazole in this study were also consistent with other reports $[17,24]$. Majority of the non-albicans Candida species 
were susceptible to ketoconazole. However, a marked resistance was observed among Candida glabrata and Candida krusei isolates. This is similar to past findings by Pfaller et al. [23] that there has been an emerging resistance to ketoconazole between the two species.

Itraconazole was the other azole antifungal drug tested in this study. Most of the Candida albicans were susceptible (83.33\%) to itraconazole with MICs $\leq 0.125 \mu \mathrm{g} / \mathrm{ml}$

(Table 3). Itraconazole is said to be among the first line antifungal drugs used against Candida species and it has a wider spectrum of efficiency against Candida albicans [25]. However, $16.67 \%$ of the isolates were resistant; $5 \%$ susceptible in dose dependent and $11.67 \%$ resistant. Incomplete therapy, overgrowth of resistant strains and subsequent infections with resistant Candida albicans strains could probably be among the factors that contributed to the resistance of $16.67 \%$ isolates to this drug. Prophylactic use of azole drugs in the treatment of Candida infections could also have contributed to the development of resistance to itraconazole. The finding is in line with other studies whereby itraconazole resistant Candida albicans accounted for $6 \%-12 \%$ of the isolates from women with vaginal candidiasis [26]. A U.S. study reported itraconazole resistance of $6 \%$ to Candida albicans isolates [17]. In this study, itraconazole resistance was highest among Candida glabrata isolates $(50 \%) ; 32.14 \%$ of the isolates were reported as susceptible in a dose-dependent manner and only $17.85 \%$ of the Candida glabrata isolates. This could be associated with clinical overt failure of antifungal azole therapy to the Candida species infection. The findings are similar with that of Gonzalez et al. [12] who reported Candida glabrata isolates resistance of $43.75 \%, 37.5 \%$ were susceptible in a dose dependent and only $18.7 \%$ were susceptible to Itraconazole among blood stream isolates.

Candida krusei was $100 \%$ susceptible to itraconazole. This is because C. krusei is intrinsically susceptible to itraconazole than the other azole drugs [17]. This finding is in agreement with a past study by Sobel et al. [17]. The other non-albicans Candida isolates (Candida parapsilosis and Candida tropicalis) were also $100 \%$ susceptible to itraconazole. This observation is consistent with other report by Dixon et al. [27] that Candida tropicalis, Candida parapsilosis and most of the non Candida albicans species are susceptible to Itraconazole.

A Candida albicans isolates were susceptible to clotrimazole $(63.33 \%)$. However, the other remaining $36.67 \%$ isolates had an MIC of $>0.5 \mu \mathrm{g} / \mathrm{ml}$, which is an indication of drug resistance. Clotrimazole has been shown to inhibit the major fungi causing systemic infection especially vaginal candidiasis at a concentration of 1 $\mu \mathrm{g} / \mathrm{ml}$ with efficacy against Candida [28]. Although, favorable results from systemic treatment of candidiasis and vaginal candidiasis have been described, some Can- dida albicans strains still show high MICs to clotrimazole. Despite the high MICs to clotrimazole, the drug is extensively used in Kenya for management of vaginal candidiasis and dermatological conditions [1]. The resistance of Candida albicans isolates (36.67\%) reported in this study could have been contributed by clinical overt failure of antifungal azole therapy resulting to the development of resistance of Candida albicans to clotrimazole [13]. These findings are in line with a report by Kangogo et al. [2] where Candida albicans susceptibility of $61 \%$ and a resistance of $39 \%$ to Clotrimazole.

Candida glabrata isolates had the highest in susceptibility to clotrimazole compared to the other Candida species isolates (Table 4). Eighty nine point two nine $(89.29 \%)$ of the isolates were susceptible. However, a marked resistance of $10.71 \%$ of the Candida glabrata isolates was recorded. This could have been contributed by subsequent infections with resistant strains of Candida glabrata and the frequent use of azole drugs for treatment of candidiasis which pose the risk of development of resistance of some of the Candida species especially the non albicans Candida species. A high resistance was observed among Candida krusei isolates in this study $(100 \%)$ probably because Candida krusei is only susceptible to Itraconazole and not to the other azole drugs [17]. These findings are in agreement with a past study by Pfaller et al. [23] that reported an emerging resistance among Candida krusei and Candida glabrata species to clotrimazole. On the other hand, two non albicans species (Candida tropicalis and Candida parapsilosis) isolated in this study were $66.67 \%$ and $100 \%$ susceptible to clotrimazole.

Topical nystatin was the only polyene antifungal drug prescribed to pregnant women in Thika District Hospital. Thus, it was the only one tested. Both Candida albicans and Candida glabrata had low susceptibility to topical nystatin $(41.67 \%$ and $42.88 \%)$ respectively in this study. However, $58.34 \%$ and $57.14 \%$ isolates respectively of the species were resistant to topical Nystatin (Table 5). Likewise, the misuse of the drug by the pregnant women due to its easily availability could have contributed to the resistance of Candida albicans and Candida glabrata isolates to the drug. This is in agreement with a previous observation that emerging resistance to topical nystatin by the two species is on the increase [29]. Candida krusei and Candida tropicalis were $50 \%$ and $33.33 \%$ susceptible to topical nystatin respectively. This could have probably been contributed by the frequent use of the drug by the pregnant women for the treatment of vaginal candidiasis that resulted to development of resistance of Candida species to the drug. The only isolate of Candida parapsilosis had an MIC of $<1.0 \mu \mathrm{g} / \mathrm{ml}$ and it was regarded susceptible (100\%). This finding is consistent with that of Kangogo et al. [2] who reported Candida 
parapsilosis susceptibility of $83 \%$ to the drug.

Susceptibility between the azole drugs and the only polyene drug used in this study showed that vaginal Candida species were less susceptible to the polyene drug used than the azole drugs. This is probably because of the difference in the mode of action between the azole and the polynes drugs. The mode of action of azoles is less altered by Candida species compared to the polyenes drugs. These findings are in agreement with the report by Okungbowa [30] that Candida species are more susceptible to azole antifungal drugs than polyenes drugs commonly used. Fungal infections are often challenging to manage; caution has to be exercised in the use of antifungal drugs to arrest any further increase in resistance. They have to be taken only under a clinician's prescripttion.

\section{Conclusion}

Candida albicans was the most prevalent species causing vaginal candidiasis in pregnant women. Majority of vaginal Candida species isolates exhibited high susceptibility to the azole drugs tested in this study. However, a tendency for lower susceptibility of some isolates to topical nystatin was observed and compared to azole drugs. An emerging resistance of non-albicans species especially Candida krusei which is resistant to all drugs used except itraconazole was also observed. Nonetheless, the susceptibility of vaginal Candida species to the azole drugs observed in this study supports the continued use of the antifungal drugs for the treatment of vaginal candidiasis in pregnant women except topical nystatin in Thika District Hospital. However, continuous surveillance on antifungal resistance to Candida species should be done in order to detect any emerging drug resistance.

\section{Acknowledgements}

We acknowledge Kenyatta University and Thika District Hospital for the approval of this research project. We thank the Hospital laboratory staff members for their valuable assistance. We are grateful to all the patients who participated in this study. Finally, we highly acknowledge the National Council for Science and Technology (NCST), Kenya for awarding a grant to carry out this project (Grant number, NCST/5/003/PG/86).

\section{REFERENCES}

[1] C. Bii, T. Ouko, E. Amukoye and W. Githinji, "Antifungal Drug Susceptibility of Candida albicans," East African Medical Journal, Vol. 79, No. 3, 2002, pp. 143-145. http://dx.doi.org/10.4314/eamj.v79i3.8894

[2] M. Kangogo, W. Wanyoike and C. Bii, "Characterization of Candida Species from Clinical Sources in Nairobi, Kenya," East African Medical Journal, Vol. 12, 2008, pp.
$34-42$.

[3] K. Hazen, "New and Emerging Yeast Pathogens," Clinical Microbiology, Vol. 8, 1995, pp. 462-478.

[4] V. Kremery and A. Barnes, "Non-albicans spp. Causing Fungaemia: Pathogenicity and Antifungal Resistance," Journal of Hospital Infection, Vol.50, 2002, pp. 243-260. http://dx.doi.org/10.1053/jhin.2001.1151

[5] M. Pfaller and D. Diekema, "Role of Sentinel Surveillance of Candidemia. Trends in Species Distribution and Antifungal Susceptibility," Journal of Clinical Microbiology Diseases, Vol. 40, 2002, pp. 3551-3557. http://dx.doi.org/10.1128/JCM.40.10.3551-3557.2002

[6] J. Chander, "A Textbook of Medical Mycology," 2nd Edition, Mehta Publishers, New Delhi, 2002, pp. 212227.

[7] F. Baker, "Handbook of Bacteriological Technique," 2nd Edition, Butterwarth and Co. Ltd., London, 1967, pp. 415-421.

[8] J. Lodder, "The Yeasts," North-Holland Publishing Co., Amsterdam, 1970, pp. 200-210.

[9] K. Hace, G. Noskin, K. Traka and S. Hiririchs, "Invasive Infection Due to Candida krusei in Immunocompromised Patients Not Treated with Fluconazole," Clinical Infectious Diseases, Vol. 20, 1995, pp. 342-347. http://dx.doi.org/10.1093/clinids/20.2.342

[10] National Committee for Clinical Laboratory Standard, "Reference Method for Broth Dilution Antifungal Susceptibility testing of Yeasts," Proposed Standard, 2002, M27-A2.

[11] S. Sandra, P. Rudolph, A. Shawn, J. Richard, J. Daniel and A. Pfaller, "Antifungal Susceptibilities of Candida Species Causing Vulvovaginitis and Epidemiology of Recurrent Cases," Journal of Clinical Microbiology, Vol. 43, No. 5, 2005, pp. 2155-2162. http://dx.doi.org/10.1128/JCM.43.5.2155-2162.2005

[12] M. Gonzalez, M. Elizondo and J. Ayala, "Trends in Species Distribution and Susceptibility of Blood Stream Isolates of Candida Collected in Monterrey Mexico to Seven Antifungal Agents," Journal of Clinical Microbiology, Vol. 46, No. 9, 2008, pp. 2902-2905. http://dx.doi.org/10.1128/JCM.00937-08

[13] R. Pelletier, J. Peter, C. Antin, M. Gonzalez, L. Wood and T. Walsh, "Emergence of Resistance of Candida albicans to Clotrimazole in HIV Infected Children: In Vitro and Clinical Correlation," Journal of Clinical Microbiology, Vol. 38, 2002, pp. 1563-1568.

[14] R. Harvey and J. Myers, "Nosocomial Fungemia in a Large Community Teaching Hospital," Archives International Medicine, Vol. 147, 1987, pp. 2117-2120. http://dx.doi.org/10.1001/archinte.1987.00370120053011

[15] B. Ogunbayo, "Isolates of Yeast from Male Contacts of Women with Vaginal Candidosis," Genitourinary Medicine, Vol. 64, 1998, pp. 135-136.

[16] E. Akortha, O. Chikwe and O. Nwaugo, "Antifungal Resistance among Candida species from Patients with Genitourinary Tract Infection Isolated in Benin City, Edo estate, Nigeria," African Journal of Microbiology Research, Vol. 3, No.11, 2009, pp. 694-699. 
[17] J. Sobel, H. Wiesentld, M. Marteus, H. Sperling and T. Chu, "Maintenance of Fluconazole Therapy for Recurrent Vulvovaginal Candidiasis," National England Journal of Medicine, Vol. 351, 2004, pp. 876-883. http://dx.doi.org/10.1056/NEJMoa033114

[18] M. Ribeiro, R. Dietze, D. Paula, D. Matta and A. Colombo, "Susceptibility Profile of Vaginal Yeast Isolates from Brazil," Mycopathology, Vol. 151, 2000, pp. 5-10. http://dx.doi.org/10.1023/A:1010909504071

[19] B. Mathema, E. Cross, E. Dun, S. Park, J. Bedell, B. Slade, L.Williams, L. Reley and D. Perlin, "Prevalence of Vaginal Colonization by Drug Resistant Candida Species in College-Age Women with Previous Exposure to Overthe Counter Azole Antifungals," Clinical Infectious Diseases, Vol. 33, 2001, pp. 23-27. http://dx.doi.org/10.1086/322600

[20] M. Pfaller, S. Diekema, L. Messer, R. Boyken and J. Hollis, "Activities of Fluconazole and Varicanazole against 1568 Recent Clinical Isolates of Candida Species Determined by Broth Microdilution Disk Diffusion and Etest Methods: Report from the ARTEMIS Global Antifungal Susceptibility Program, 2001," Journal of Clinical Microbiology, Vol. 41, 2003, pp. 1440-1446. http://dx.doi.org/10.1128/JCM.41.4.1440-1446.2003

[21] K. Goa and E. Barrdell, "Fluconazole and Update of Its Pharmacodynamic and Pharmacokinetic Properties and Therapeutic Use in Major Superficial and Systemic Mycoses in Immunocompromised Patients," Drugs, Vol. 50, 1995, pp. 658-690. http://dx.doi.org/10.2165/00003495-199550040-00007

[22] J. Klastersky, "Prevention and Therapy of Fungal Infection in Cancer Patients," Support Care Cancer, Vol. 3, No. 6, 1995, pp. 393-410. http://dx.doi.org/10.1007/BF00364979

[23] M. Pfaller, R. Messer and A. Hajjeh, "Trends in Species Distribution and Susceptibility to Fluconazole among
Blood Stream Isolates of Candida Species in United States," Diagnostic Microbiology Diseases, Vol. 33, 1999, pp. 217-222. http://dx.doi.org/10.1016/S0732-8893(98)00160-6

[24] T. White, K. Marr and R. Bowden, "Clinical Cellular and Molecular Factors that Contribute to Antifungal Drug Resistance," Clinical Microbiology Revision, Vol. 11, No. 2, 1998, pp. 382-402.

[25] S. Redding, G. Smith, M. Farinacci, A. Rinaldi, J. Forthegill, A. Rhine-Chalberg and M. Pfaller, "Resistance of Candida albicans to Fluconazole during Treatment of Oropharyngeal Candidiasis in a Patient with AIDS: Documentation by in Vitro Susceptibility Testing and DNA Subtype Analysis," Clinical Infectious Diseases, Vol. 18, 1994, pp. 240-242. http://dx.doi.org/10.1093/clinids/18.2.240

[26] S. Newman, "Clinically Significant Mucosal Candidiasis Resistant to Fluconazole Treatment in Patients with AIDS," Clinical Infectious Diseases, Vol. 19, 1994, pp. 684-686. http://dx.doi.org/10.1093/clinids/19.4.684

[27] D. Dixon, M. McNeil, M. Cohen, B. Gellin and J. La Montagne, "Fungal Infections: A Growing Threat," Public Health Report, Vol. 11, 1996, pp. 226-235.

[28] D. Grahame-Smith and J. Arsonson, "Oxford Textbook of Clinical Pharmacology and Drug Therapy," 2nd Edition, Oxford University Press Inc., New York 1992, p. 559.

[29] D. Law and C. Moore, "High Prevalence of Antifungal resistance in Candida spp. from Patients with AIDS," Journal of Antimicrobial Chemotherapy, Vol. 34 No. 5, 1994, pp. 659-668. http://dx.doi.org/10.1093/jac/34.5.659

[30] F. Okungbowa, O. Isuehuemhen and A. Dede, "The Distribution, Frequency of Candida species in the Genitourinary Tract among Symptomatic Individuals in Nigeria Cities," Revised Iberoam Microbiology, Vol. 20, 2003, pp. 60-63. 